in vivo $34: 3361-3365(2020)$

doi:10.21873/invivo.12174

\title{
Risk Factors for Severe Complications in Ovarian Cancer Surgery
}

\author{
EVA KATHARINA EGGER ${ }^{1}$, NATASCHA KOHLS ${ }^{1}$, MATTHIAS B. STOPE ${ }^{1}$, MATEJA CONDIC ${ }^{1}$, \\ MIGNON-DENISE KEYVER-PAIK ${ }^{1}$, DOMINIQUE KÖNSGEN ${ }^{1}$, TOBIAS HILBERT ${ }^{2}$, \\ SVEN KLASCHIK ${ }^{2}$, DANIEL EXNER ${ }^{3}$, TIM VILZ $^{3}$ and ALEXANDER MUSTEA ${ }^{1}$ \\ ${ }^{1}$ Department of Gynecology and Gynecological Oncology, University Hospital Bonn, Bonn, Germany; \\ ${ }^{2}$ Department of Anesthesiology and Intensive Care Medicine, University Hospital Bonn, Bonn, Germany; \\ ${ }^{3}$ Department of Surgery, University Hospital Bonn, Bonn, Germany
}

\begin{abstract}
Backround: Due to extensive surgical intervention for macroscopic complete cytoreduction in epithelial ovarian cancer (EOC) patients, severe complications in the postoperative course are possible. Patients and Methods: A total of 345 EOC patients who underwent cytoreductive surgery were retrospectively evaluated regarding risk factors for an unfavorable postoperative course. Possible pre-, intraand postoperative risk factors were statistically analyzed performing multivariate ordinal logistic regression. Results: A total of 345 EOC patients underwent cytoreductive surgery. There were no complications in 114 patients, mild complications in 114 patients and severe complications in 117 patients. The risk factor evaluation identified age $(p=0.049)$, smoking $(p=0.032)$ and duration of surgery $(p<0.0001)$ as significant factors for severe postoperative morbidity. Conclusion: In EOC patients age, smoking and the duration of surgery have significant impact on the postoperative course. Only the duration of surgery can be positively influenced by a well-trained EOC team.
\end{abstract}

In epithelial ovarian cancer (EOC) the prognostic impact of macroscopic complete cytoreduction has been shown unequivocally. Often, complex surgery will be needed harbouring the risk of severe postoperative complications (1). These postoperative complications may delay adjuvant therapy and therefore have a negative impact on survival

This article is freely accessible online.

Correspondence to: Eva Egger, Department of Gynecology and Gynecological Oncology, University Hospital Bonn, VenusbergCampus 1, 53127 Bonn, Germany. Phone: +49 22828715447, Fax: +49 22828716091, e-mail: eva-katharina.egger@ukbonn.de

Key Words: Ovarian cancer, postoperative complications, Postoperative period, surgical oncology.
(2). Using the Memorial Sloan Kettering Cancer Center secondary surgical event score we classified all postoperative complications within the first 60 days after surgery from grade 1 to 5 . The aim of this study was the identification of possible risk factors for an unfavorable postoperative course (3).

\section{Patients and Methods}

This retrospective study was conducted in accordance with the standards of the local ethics committe of the medical faculty of the Rheinische Friedrich Wilhelms University, Bonn, Germany (Nr: $314 / 20$ ). All 345 patients who underwent cytoreductive surgery for EOC between 2004 and 2016 were included in this study and data were collected and analyzed. Postoperative complications were assessed by the Memorial Sloan Kettering Cancer Center secondary surgical event score (3). Histologies and surgical reports were used for a retrospective determination of the peritoneal cancer index (4). For statistical analysis, patients were divided into two groups; those with no or mild complications (secondary surgical events grade 1 and 2) and those with severe complications (secondary surgical events grade 3 to 5 ).

Possible risk factors for severe secondary surgical events were analyzed by multivariate ordinal logistic regression. The quality review was performed by Pearson and Deviance tests. Further data were analyzed by binary ordinal logistic regression. Differences were defined to be significant when $p \leq 0.05$. All statistical analyses were performed using Minitab Version 18.

\section{Results}

A total of 345 patients underwent cytoreductive surgery for EOC. Patient variables analyzed in the multivariate analysis are listed in Table I. Table II shows all secondary surgical events in detail while Table III shows all graded secondary surgical events and the number of patients affected. 7 patients died in the postoperative course within the first 60 days after surgery. 1 patient suffered a heart attack, 1 patient with a known aortic stenosis experienced postoperative 
Table I. Patient characteristics, surgical details and histology.

\begin{tabular}{|c|c|}
\hline Variable & Result \\
\hline Mean age & 60 years $(16-85)$ \\
\hline $\begin{array}{l}\text { American Society of Anaesthesiologists } \\
\text { (ASA) risk classification }\end{array}$ & $\begin{array}{c}\text { Evaluated in } 345 \\
\text { patients }\end{array}$ \\
\hline 1 & 47 \\
\hline 2 & 203 \\
\hline 3 & 94 \\
\hline 4 & 1 \\
\hline Body mass index & $\begin{array}{c}\text { Evaluated in } 338 \\
\text { patients }\end{array}$ \\
\hline$<19$ & 11 patients \\
\hline $19-24$ & 162 patients \\
\hline $25-30$ & 108 patients \\
\hline $30.1-40$ & 44 patients \\
\hline$>40$ & 13 patients \\
\hline \multicolumn{2}{|l|}{ Comorbidities } \\
\hline $\begin{array}{l}\text { History of thrombembolic events } \\
\text { (heart attac, thrombosis, embolism) }\end{array}$ & 47 patients \\
\hline Diabetes mellitus & 27 patients \\
\hline Smokers & 48 patients \\
\hline FIGO-Stages & 345 patients \\
\hline $\mathrm{IA} / \mathrm{IB}$ & 48 patients \\
\hline IIA-IIB & 21 patients \\
\hline IIIA & 4 patients \\
\hline IIIB & 16 patients \\
\hline IIIc & 216 patients \\
\hline IV & 40 patients \\
\hline First diagnosis of EOC & 301 patients \\
\hline Recurrent EOC & 44 patients \\
\hline $\begin{array}{l}\text { Neoadjuvant chemotherapy } \\
\text { and secondary cytoreduction }\end{array}$ & 137 patients \\
\hline Primary debulking surgery & 208 patients \\
\hline Median peritoneal cancer index & 10 (range $=0-32)$ \\
\hline Completeness of cytoreduction & 227 patients \\
\hline Incomplete cytoreduction & 113 patients \\
\hline No Information on completeness & 5 patients \\
\hline Median operating time & $372 \min (135-695)$ \\
\hline Median number of erythrocyte concentrates & $4.8($ range $=0-38)$ \\
\hline Median time in intensive care unit & 1 day (range $=0-43$ days \\
\hline $\begin{array}{l}\text { Median duration of postoperative } \\
\text { mechanical ventilation }\end{array}$ & $5.8 \mathrm{~h}($ range $=0-576 \mathrm{~h})$ \\
\hline \multicolumn{2}{|l|}{ Histology } \\
\hline Serous & 309 patients \\
\hline Mucinous & 14 patients \\
\hline Endometroid & 17 patients \\
\hline Clear cell & 4 patients \\
\hline Seromucinous & 1 patient \\
\hline Lymph node dissection & 281 patients \\
\hline No Lymph node dissection & 64 patients \\
\hline
\end{tabular}

cardiac decompensation while 2 patients died of septic pneumonia in the late postoperative course. 3 patients experienced a septic shock, 2 due to an anastomotic leckage and 1 due to an abscess followed by an enterocutaneous fistula. The most common secondary surgical events were pleural effusion, wound infection, and paralytic ileus.
Table II. Postoperative complications (secondary surgical events) in the first 60 days after surgery.

\begin{tabular}{|c|c|c|}
\hline $\begin{array}{l}\text { Specified secondary } \\
\text { surgical events }\end{array}$ & $\begin{array}{l}\text { Patients } \\
\text { [number] }\end{array}$ & $\begin{array}{c}\text { Percentage } \\
{[\%]}\end{array}$ \\
\hline Anastomotic leackage & 24 & 6.95 \\
\hline Abscess around the anastomosis & 10 & 2.89 \\
\hline Peritonitis more than localized & 17 & 4.92 \\
\hline Burst abdomen & 12 & 3.48 \\
\hline Ileus & 1 & 0.29 \\
\hline Paralytic Ileus & 46 & 13.33 \\
\hline Stenosis of the anastomosis & 1 & 0.29 \\
\hline Clostidium difficile infection & 5 & 1.45 \\
\hline Hartmann stump insufficiency & 1 & 0.29 \\
\hline Ureter lesion & 1 & 0.29 \\
\hline Enterocutane fistula & 2 & 0.58 \\
\hline Enterovesical fistula & 1 & 0.29 \\
\hline Rectovaginal fistula & 6 & 1.74 \\
\hline Billary fistula & 1 & 0.29 \\
\hline Pancreatic fistula & 6 & 1.74 \\
\hline Pancreatitis & 2 & 0.58 \\
\hline Deep venous thrombosis & 27 & 7.82 \\
\hline Lung embolia & 10 & 2.89 \\
\hline $\begin{array}{l}\text { Non-ST-segment elevation myocardial } \\
\text { infarction }\end{array}$ & 9 & 2.61 \\
\hline ST-segment elevation myocardial infarction & 2 & 0.58 \\
\hline Tachyarrythmia absoluta & 8 & 2.32 \\
\hline Artrial fibrillation & 4 & 1.16 \\
\hline Atrioventricular -Bloc & 1 & 0.29 \\
\hline Asystoly with successful reanimation & 2 & 0.58 \\
\hline Stroke & 1 & 0.29 \\
\hline Pleural effusion & 80 & 23.19 \\
\hline Pneumonia & 19 & 5.51 \\
\hline Secondary haemorrhage & 10 & 2.89 \\
\hline Wound infection & 75 & 21.74 \\
\hline Lymphocele & 42 & 12.17 \\
\hline Pyelonephritis & 2 & 0.58 \\
\hline Urinary tract infection & 28 & 8.12 \\
\hline Urinary stasis & 15 & 4.35 \\
\hline Kidney infarction & 4 & 1.16 \\
\hline Renal insufficiency, partly transient & 7 & 2.03 \\
\hline Port infection & 3 & 0.87 \\
\hline Central venous catheter infection & 2 & 0.58 \\
\hline Transfusion reaction & 2 & 0.58 \\
\hline Hepatitis $\mathrm{C}$ due to fresh frozen plasma & 1 & 0.29 \\
\hline Haematothorax & 1 & 0.29 \\
\hline Sepsis & 11 & 3.19 \\
\hline Postoperative delirium & 8 & 2.32 \\
\hline Transient postoperative nerval irritation & 28 & 8.12 \\
\hline
\end{tabular}

The multivariate ordinal logistic regression analysis of 344 patient data (the data of 1 patient was missing for the duration of surgery) identified smoking $(p=0.032)$ as the strongest preoperative factor for the development of severe complications. The age of the patients $(p=0.049)$ and the duration of surgery $(p<0.001)$ were the two other risk factors significantly associated with severe complications. Table IV shows the results 
Table III. Postoperative complications graded according to the MSKCC secondary surgical event score.

\begin{tabular}{lcc}
\hline $\begin{array}{l}\text { Secondary } \\
\text { surgical events }\end{array}$ & $\begin{array}{c}\text { Patients } \\
\text { [number] }\end{array}$ & $\begin{array}{c}\text { Percentage } \\
{[\%]}\end{array}$ \\
\hline None & 114 & 33.04 \\
G1 & 42 & 12.17 \\
G2 & 72 & 20.87 \\
G3 & 69 & 20.00 \\
G4 & 41 & 11.88 \\
G5 & 7 & 2.02 \\
\hline
\end{tabular}

of the mulitvariate analysis. By performing binary logistic regression with 340 patient data (data on the completeness of cytoreduction was missing in 5 surgery reports), we found a significant decrease in complete cytoreduction with increasing age of patients $(p=0.010)$. The risk of leaving surgery with a residual disease increased 1.29-fold every ten years with increasing patient age. The age of the patients was not related to a prolonged hospital stay $(p=0.244)$.

The body mass index, available in 338 patients, was no predictor for residual disease $(p=0.820 ; \mathrm{OR}=1.03)$ or the duration of surgery $(p=0.383)$. The duration of surgery had no impact on postoperative thrombembolic events $(p=0.197)$ or the number of erythrocyte concentrates received $(p=0.770)$. The risk of thrombembolic events was reduced in the group of patients with a history of thrombembolic events ( $\mathrm{OR}=0.715)$.

The available data on the peritoneal cancer index in 330 patients demonstrated no significant correlation with a preoperative anemia or the duration of the postoperative intensive care. However, a peritoneal cancer index of more than 15 correlated with a higher incidence of a postoperative pancreatic fistula $(\mathrm{OR}=0.083)$. The peritoneal cancer index had significant impact on the duration of surgery $(p<0.001)$ and the completeness of cytoreduction $(p<0.001 ; \mathrm{OR}=0.800)$. The significant correlation between the peritoneal cancer index and Ca125 ( $p=0.034$ ) was negligible in the metric set (Figure 1).

The risk of a preoperative anemia was 1.57 -fold higher in the group of patients with neoadjuvant chemotherapy than in the group of patients without neoadjuvant chemotherapy.

\section{Discussion}

Optimal cytoreduction in EOC patients aims to increase overall survival but harbours the risk of increased morbidity and a prolonged recovery which in turn decreases survival (5). The preoperative prediction of postoperative complications would be ideal to define high-risk patients. Despite intensive efforts in the preoperative work up, this remains difficult. In the present study, smoking was identified
Table IV. Multivariate analysis of potential risk factors (age, preoperative anemia, ASA, BMI, history of thrombembolic events, diabetes, elevated creatinin levles, neoadjuvant chemotherapy, smoking, recurrent disease, primary disease, number of transfused erythrocytes, complete or incomplete resection, duration of postoperative mechanical ventilation, duration of intensive care).

\begin{tabular}{lccr}
\hline Factor & Coefficient & Odds ratio & $p$-Value \\
\hline Age & -0.020 & 0.98 & 0.049 \\
Smoking & 0.683 & 1.98 & 0.032 \\
Duration of surgery & -0.004 & 1.00 & $<0.001$ \\
\hline
\end{tabular}

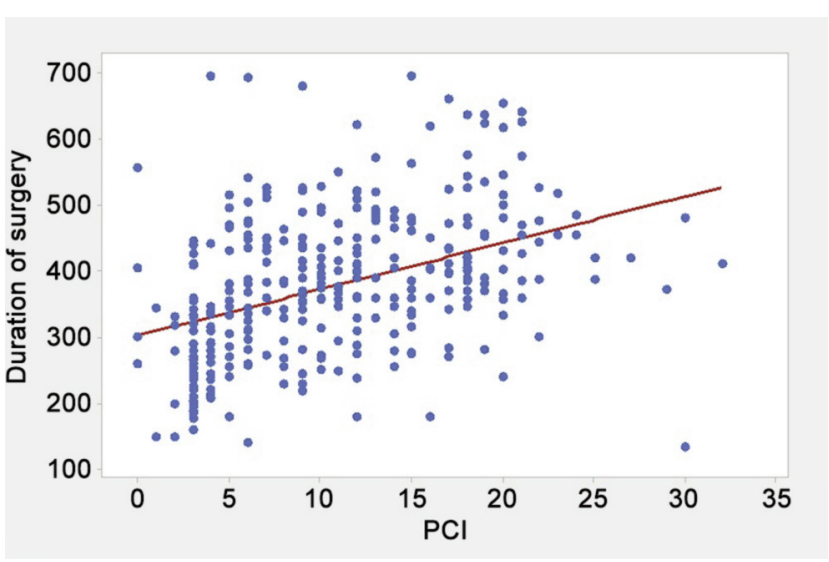

Figure 1. Duration of surgery and PCI.

as the strongest predictor for severe complications. The age of the patients and the duration of surgery were two other significant predictors of severe complications. Smoking in general shows an increased overall morbidity with wound complications, infections, pulmonary and neurological complications (6). The analysis of the database of the National Surgical Quality Improvement Program (NASQIP) identified smoking, elevated preoperative creatinine levels (above $1.5 \mathrm{mg} / \mathrm{dl}$ ) and insulin-dependent and non-insulindependent diabetes as significant risk factors for a reoperation. Reoperation shortly after initial surgery increases morbidity and mortality (7-10). We did not find a correlation between diabetes and morbidity or an elevated creatinin and morbidity. But creatinin levels were elevated in only 3 patients. In line with the above, the evaluation of more than 500,000 patients data from the American College of Surgeons in NSQIP identified smoking as a significant promoter of pneumonia, cardiac arrest, myocardial infarction, stroke, sepsis, septic shock, organ space infection and increased postoperative mortality (10). 
An age above 75 years has been determined as a risk factor for higher postoperative morbidity and mortality. In general surgery in the elderly is feasible but the risk for increased severe morbidity and increased mortality is almost $40 \%$. In addition, adjuvant chemotherapy may be delayed or not administered at all. Even when complete cytoreduction is dispensed due to the age of the patient, incomplete surgery also bears the risk of increased perioperative morbidity. Especially in patients over 80 years of age, FIGO stage IV, low albumin levels, and higher risk classification according to the American Society of Anaesthesiologists (ASA), morbidity and mortality increases rapidly (11). Data analysis of the NSQIP demonstrated a linear progression of morbidity and an exponential progression of mortality with increasing age. The increase in morbidity and mortality was seen despite the absence of further risk factors at the age of 70 and over. Predictive factors for morbidity and mortality in the elderly patients were urgent surgery, unintentional weight loss, preoperative anemia, and blood transfusions. Preoperative anemia and blood transfusions had no significant impact on severe morbidity in our cohort. Furthermore, an age over 80 years was associated with the highest risk for wound infections without any correlation to other risk factors (12). The frailty of aging itself without additional specific comorbidities is not usually noticeable in the normal state. But the stress of surgery requires reserve capacities which may not be available in older patients. Therefore, age may sometimes be the only assessable risk factor in this patient cohort (13).

In addition to the experience of the surgeon, the complexity of the surgical intervention significantly determines the duration of the surgery and the postoperative morbidity, especially in the older patients (12). An increase in surgery duration of only 30 minutes in patients with EOC results in $17 \%$ more cardiovascular events, $7 \%$ more respiratory events, and $15 \%$ more wound infections (12). Surgery duration of more than 10 hours and an ASA risk classification of 3 or more were the only significant factors for grade 3 and 4 secondary surgical events in patients with pseudomyxoma peritonei (14). The Tennesse Surgical Quality Collaborative showed that the risk for secondary surgical events increases significantly after 2.1 hours of surgery. A significant risk of deep infections at the surgical site begins only after 42 minutes of surgery. Each additional hour of surgery time supports the development of a postoperative sepsis (15). Even in laparoscopic procedures, the duration of surgery represents a significant risk factor for postoperative complications (16). Well trained surgeons minimize the duration of surgery which results in a reduction in mortality of $69 \%$ (17).

The ASA risk classification was irrelevant in our study for severe secondary surgical events. This could be due to the previous policy of the clinic to administer neoadjuvant chemotherapy whenever aszites more than $500 \mathrm{cc}$ was present. Therefore, severely and critically affected EOC patients may already have been excluded. Other studies have indeed shown that a higher ASA risk classification correlates with the grade of secondary surgical events. Especially in older patients, the ASA risk classification is significantly associated with severe secondary surgical events $(11,12,14$, 18). In a retrospective study even a $72 \%$ correct identification of high-risk patients was suggested based on the combination of ASA risk classification, low albumin levels, aszites, bleeding disorders, urgency of surgery, higher extended procedure score, and age of the patients (18).

Obesity is a known risk factor for decreased overall survival in patients with EOC (19). In some studies, morbid obesity, indicated by a body mass index of more than 39.9, has been associated with severe secondary surgical events (20). Other studies show that obese patients are only at risk for impaired wound healing (21). In our study the body mass index had no significant influence on the postoperative course, incomplete cytoreduction, or a prolonged duration of surgery. Nevertheless, it should be noted that morbid obesity with a body mass index of more than 39.9 was present in only 13 patients.

The strength of our study lies in its homogenous data set, since only those EOC patients who were actually assigned to cytoreductive surgery with the intention of complete resection were included in our analysis. However, due to the retrospective nature of the study, a possible bias in patient selection cannot be excluded.

\section{Conclusion}

In EOC patients the risk factors of age, smoking and the duration of surgery have a significant impact on the postoperative morbidity and mortality. Only the duration of surgery may be positively influenced by a well-trained EOC team. Therefore, detailed preoperative assessment of the expected surgical complexity in EOC patients is essential. The expertise of the EOC surgeon should be appropriate for the level of complexity of EOC surgery in order to reduce postoperative morbidity and mortality due to shorter duration of surgery.

\section{Conflicts of Interest}

The Authors declare no conflicts of interest.

\section{Authors' Contributions}

Conception and design: E.K. Egger, A. Mustea; Data analysis and interpretation: E.K. Egger, M. Condic, M.D. Keyver-Paik; Investigation: E.K. Egger, N. Kohls, D. Könsgen, S. Klaschik, T. Hilbert; Writing-original draft preparation: E.K. Egger, D. Exner; Writing-review and editing: T. Vilz, M.B. Stope; Supervision: A. Mustea. 


\section{References}

1 Koscielny A, Ko A, Egger EK, Kuhn W, Kalff JC and KeyverPaik MD: Prevention of anastomotic leakage in ovarian cancer debulking surgery and its impact on overall survival. Anticancer Res 39(9): 5209-5218, 2019. PMID: 31519635. DOI: 10.21873/ anticanres. 13718

2 Grimm C, Harter P, Alesina PF, Prader S, Schneider S, Ataseven B, Meier B, Brunkhorst V, Hinrichs J, Kurzeder C, Heitz F, Kahl A, Traut A, Groeben HT, Walz M and du Bois A: The impact of type and number of bowel resections on anastomotic leakage risk in advanced ovarian cancer surgery. Gynecol Oncol 146(3): 498-503, 2017. PMID: 28610745. DOI: 10.1016/j.ygyno. 2017.06.007

3 Strong VE, Selby LV, Sovel M, Disa JJ, Hoskins W, Dematteo $\mathrm{R}$, Scardino P and Jaques DP: Development and assessment of memorial sloan kettering cancer center's surgical secondary events grading system. Ann Surg Oncol 22(4): 1061-1067, 2015. PMID: 25319579. DOI: 10.1245/s10434-014-4141-4

4 Lampe B, Kroll N, Piso P, Forner DM and Mallmann P: Prognostic significance of sugarbaker's peritoneal cancer index for the operability of ovarian carcinoma. Int J Gynecol Cancer 25(1): 135-144, 2015. PMID: 25423317. DOI: 10.1097/IGC. 0000000000000327

5 Aletti GD, Dowdy SC, Podratz KC and Cliby WA: Relationship among surgical complexity, short-term morbidity, and overall survival in primary surgery for advanced ovarian cancer. Am J Obstet Gynecol 197(6): 676.e1-676.e7, 2007. PMID: 18060979. DOI: 10.1016/j.ajog.2007.10.495

6 Grønkjær M, Eliasen M, Skov-Ettrup LS, Tolstrup JS, Christiansen AH, Mikkelsen SS, Becker U and FlensborgMadsen T: Preoperative smoking status and postoperative complications: A systematic review and meta-analysis. Ann Surg 259(1): 52-71, 2014. PMID: 23799418. DOI: 10.1097/SLA. 0b013e3182911913

7 Birkmeyer JD, Hamby LS, Birkmeyer CM, Decker Mv, Karon $\mathrm{NM}$ and Dow RW: Is unplanned return to the operating room a useful quality indicator in general surgery? Arch Surg 136(4): 405-411, 2001. PMID: 11296110. DOI: 10.1001/archsurg. 136.4.405

8 Rama-Maceiras P, Rey-Rilo T, Moreno-Lopez E, Molins-Gauna N, Sanduende-Otero Y and Pensado-Castiñeiras A: Unplanned surgical reoperations in a tertiary hospital: perioperative mortality and associated risk factors. Eur J Anaesthesiol 28(1): 10-15, 2011. PMID: 21166109. DOI: 10.1097/eja. 0b013e32833e33b0

9 Kazaure HS, Chandra V and Mell MW: Unplanned reoperations after vascular surgery. J Vasc Surg 63(3): 730-736, 2016. PMID: 26553950. DOI: $10.1016 /$ j.jvs.2015.09.046

10 Turan A, Mascha EJ, Roberman D, Turner PL, You J, Kurz A, Sessler DI and Saager L: Smoking and perioperative outcomes. Anesthesiology 114(4): 837-846, 2011. PMID: 21372682. DOI: $10.1097 / A L N .0 b 013 e 318210 f 560$

11 Langstraat C, Aletti GD and Cliby WA: Morbidity, mortality and overall survival in elderly women undergoing primary surgical debulking for ovarian cancer: A delicate balance requiring individualization. Gynecol Oncol 123(2): 187-191, 2011. PMID: 21794902. DOI: 10.1016/j.ygyno.2011.06.031

12 Turrentine FE, Wang H, Simpson VB and Jones RS: Surgical risk factors, morbidity, and mortality in elderly patients. J Am
Coll Surg 203(6): 865-877, 2006. PMID: 17116555. DOI: 10.1016/j.jamcollsurg.2006.08.026

13 Evers BM, Townsend CM and Thompson JC: Organ physiology of aging. Surg Clin North Am 74(1): 23-39, 1994. PMID: 8108769. DOI: $10.1016 /$ S0039-6109(16)46226-2

14 Saxena A, Yan TD, Chua TC and Morris DL: Critical assessment of risk factors for complications after cytoreductive surgery and perioperative intraperitoneal chemotherapy for pseudomyxoma peritonei. Ann Surg Oncol 17(5): 1291-1301, 2010. PMID: 20039212. DOI: $10.1245 / \mathrm{s} 10434-009-0875-9$

15 Daley BJ, Cecil W, Clarke PC, Cofer JB and Guillamondegui OD: How slow is too slow? Correlation of operative time to complications: an analysis from the Tennessee Surgical Quality Collaborative. J Am Coll Surg 220(4): 550-558, 2015. PMID: 25728140. DOI: 10.1016/j.jamcollsurg.2014.12.040

16 Jackson TD, Wannares JJ, Lancaster RT, Rattner DW and Hutter MM: Does speed matter? The impact of operative time on outcome in laparoscopic surgery. Surg Endosc 25(7): 2288-2295, 2011. PMID: 21298533. DOI:10.1007/s00464-010-1550-8

17 Bristow RE, Zahurak ML, Diaz-Montes TP, Giuntoli RL and Armstrong DK: Impact of surgeon and hospital ovarian cancer surgical case volume on in-hospital mortality and related shortterm outcomes. Gynecol Oncol 115(3): 334-338, 2009. PMID: 19766295. DOI: 10.1016/j.ygyno.2009.08.025

18 Cham S, Chen L, St. Clair CM, Hou JY, Tergas A I, Melamed A, Ananth CV, Neugut AI, Hershman DL and Wright JD: Development and validation of a risk-calculator for adverse perioperative outcomes for women with ovarian cancer. Am J Obstet Gynecol 220(6): 571.e1-571.e8, 2019. PMID: 30771346. DOI:10.1016/j.ajog.2019.02.019

19 Nagle CM, Dixon SC, Jensen A, Kjaer SK, Modugno F, deFazio A, Fereday S, Hung J, Johnatty SE, Australian Ovarian Cancer Study Group; Fasching PA, Beckmann MW, Lambrechts D, Vergote I, Van Nieuwenhuysen E, Lambrechts S, Risch H A, Rossing MA, Doherty JA, Wicklund KG, Chang-Claude J, Goodman MT, Ness RB, K Moysich K, Heitz F, du Bois A, Harter P, Schwaab I, Matsuo K, Hosono S, Goode EL, Vierkant RA, Larson MC, Fridley BL, Høgdall C, Schildkraut JM, Weber RP, Cramer DW, Terry KL, Bandera EV, Paddock L, Rodriguez-Rodriguez L, Wentzensen N, Yang HP, Brinton LA, Lissowska J, Høgdall E, Lundvall L, Whittemore A, McGuire V, Sieh W, Rothstein J, Sutphen $\mathrm{R}$, Anton-Culver H, Ziogas A, Pearce CL, Wu AH and Webb PM: Ovarian Cancer Association Consortium Obesity and survival among women with Ovarian cancer: results from the Ovarian Cancer Association Consortium. Br J Cancer 113(5): 817-826, 2015. PMID: 26151456. DOI: 10.1038/bjc.2015.245

20 Kumar A, Bakkum-Gamez JN, Weaver AL, McGree ME and Cliby WA: Impact of obesity on surgical and oncologic outcomes in ovarian cancer. Gynecol Oncol 135(1): 19-24, 2014. PMID: 25110330. DOI: 10.1016/j.ygyno.2014.07.103

21 Smits A, Lopes A, Das N, Kumar A,Cliby W, Smits E, Bekkers R, Massuger L and Galaal K: Surgical morbidity and clinical outcomes in ovarian cancer - the role of obesity. BJOG 123(2): 300-308, 2016. PMID: 26331299. DOI: 10.1111/14710528.13585

Received September 8, 2020

Revised September 17, 2020 Accepted September 21, 2020 